Article

\title{
A Methodology for Defining Electricity Demand in Energy Simulations Referred to the Italian Context
}

\author{
Paola Caputo *, Costa Gaia and Valentina Zanotto \\ Department of Architecture, Built Environment and Construction Engineering, Politecnico di Milano, \\ Via Bonardi 9, 20133 Milano, Italy; E-Mails: gaia.costa@mail.polimi.it (C.G.); \\ valentina.zanotto@mail.polimi.it (V.Z.) \\ * Author to whom correspondence should be addressed; E-Mail: paola.caputo@polimi.it; \\ Tel.: +39-023-999-488; Fax: +39-023-999-484.
}

Received: 26 September 2013; in revised form: 21 November 2013 / Accepted: 22 November 2013 / Published: 2 December 2013

\begin{abstract}
Electricity consumption in Europe is constantly increasing, despite the fact that in recent years, huge efforts in terms of programs and regulations have been made towards energy demand reduction and energy systems improvement. Since the electricity demand affects both the operation of the supply and distribution plants and the thermal loads of buildings, the importance of providing a proper definition of demand profiles is evident. The main aim of the paper is to provide a set of standard electricity profiles that can reasonably be adopted as input in energy simulations related to the built environment, with particular regards to the Italian context. The work presented in this paper originated within a wider long lasting research aimed at developing a platform for buildings' energy simulations at district level, with particular reference to the Italian conditions. In this context, it was necessary to define hourly profiles regarding both occupancy and electricity use for lighting and appliances related to different building uses and typologies. For this purpose, the main methods and references for defining electricity loads in buildings were evaluated and average hourly profiles were accordingly developed for residential and commercial buildings. Then the related internal gains were determined and compared to the current Italian standards.
\end{abstract}

Keywords: electricity demand in buildings; internal gains; dynamic simulations; district energy systems 


\section{Introduction}

In Europe, cities are currently responsible for approximately $70 \%$ of the overall primary European energy consumption, and this share is expected to increase to $75 \%$ by 2030 [1,2]. As defined by European Directive 31 [3], member States have to ensure that, by 31 December 2020, all new buildings will be close to zero-energy buildings. However, since the number of existing buildings is very high compared to the number of new ones, the reduction of energy demand in existing buildings represents the main challenge in improving the global energy system [4].

Moreover, it is well known that the European Union (EU) policies and measures to achieve the Energy 2020 goals will continue to deliver beyond 2020, helping to reduce emissions by about $40 \%$ by 2050: a big and ambitious effort towards the objective of low carbon communities [5]. This gives an indication of the level of effort and change, both structural and social, which will be required to reach the necessary emissions reduction. Together with supply-side policies aimed to promote the shift from fossil fuels to renewable energy sources [6], there is a growing trend for policy initiatives that focus on improving energy efficiency in an attempt to reduce energy demand and decouple it from the economic growth $[7,8]$.

In this context, precise information about electricity consumption represents a fundamental requirement for the design and implementation of energy efficiency measures and of on-site electricity generation [9].

The present paper originates from a study $[10,11]$ carried out in the framework of a wider research led by the Italian Agency for New Technologies, Energy and Sustainable Economic Development (ENEA) and aimed at developing an energy simulation and optimization platform at district level, called Optimal DESign for Smart Energy (ODESSE) [12], specifically referred to the Italian context. The platform consists in one-module that models the buildings' energy behavior and providing hourly heating and cooling demands as results, and several other modules representing the operation of systems and plants for power, heating and cooling generation, energy storage and management. As in other dynamic simulation tools, the module simulating the building behavior needs the definition of climatic, geometric and thermo-physical characteristics, as well as the definition of hourly profiles for occupancy and for the operation of artificial lighting and electrical appliances. As a consequence, when considering all the buildings included in the overall energy system at the district level, it is also possible to determine the total electricity which has to be provided either by the modeled components, by micro-grids or by the national grid. Due to the liberalization of the electricity and renewable energies sectors, this can also help other objectives as ensure electrical supply and its quality [13].

The presented study focuses on the definition of the necessary usage patterns, expressed in terms of hourly profiles for occupancy and operation of artificial lighting and other electrical devices for different buildings and their uses and typologies. It also takes into account that they do not affect only the building electricity demand, connected to the operation of power plants and control systems, but also its heat balance and, therefore, the heating and cooling demands.

The final aim is the definition of standard electricity profiles that can be useful for dynamic simulations and for the evaluation of energy efficiency measures: for this reason, devices that are not commonly installed and peculiarities regarding their operation are not specifically taken into account. 
In a second instance, further inquiries were carried out with particular regard to models and methodologies aimed to evaluate electricity demand in the built environment, as described in the following Section 2.

\section{Framework of Reference}

Generally speaking, energy consumption data arise from studies that can be sorted into two different kinds of approaches, explained in detail below. These approaches differ according to the hierarchical position of the inputs taken into account or when compared to the analyzed sector (the considered building typology) or district [14].

The first one is the top-down approach. This kind of methodology treats the analyzed sector as an energy sink and attributes the specific energy consumption estimated according to macro-variables. The top-down approach is commonly adopted in supply analysis based on long-time projections of energy demand according to historic response, but they are unable to model discontinuous advances in technology or to identify the end-use key areas for improvements.

Differently, the bottom-up approach adopts input data from a lower level (such as individual or groups of buildings) and extrapolates the results for the whole sector according to the representative weight of the sample considered. It has the capability of discerning the effect of occupant behavior, and this is of particular benefit in modeling the residential sector or some specific end-uses. Bottom-up approaches can be based on statistical methods that perform a regression analysis of historical information to attribute consumption data to particular end-uses, possibly accounting for macroeconomic regional or national indicators and therefore sharing some of the strengths of the top-down approach. Another type of bottom-up approach is based on engineering methods, which combine data on the use of appliances and systems with heat transfer and thermodynamic relationships. This kind of models require a highly detailed input data and does not rely on historical information, but it can be extremely complex, both because of the extent of required information and because of the recourse to calculation and simulation techniques.

Since the use of realistic detailed profiles is essential when assessing the possibility of a positive end-users interaction with the local generation system through load rescheduling or curtailment strategies [15], a bottom-up approach can be proven more suitable. Although the recourse to simulation methods can facilitate the development of general loads (referred to a typical meteorological year or design day) and can account for the use of specific technologies, the use of historical data series analysis through forecasting techniques is necessary in case of end-uses such as the electrical ones, with a high dependence on occupant behavior, which is otherwise difficult to estimate [15].

Chioua et al. [16], for instance, present a high spatial resolution model of energy use in residential buildings based on the American Time Use Survey (ATUS) data, through a bootstrap sampling method. The results indicate the model's overall robustness and verify its ability to simulate realistic residential energy use load profiles. The work presented by Richardson et al. [17] proposes a detailed method to generate realistic statistical occupancy time-series data for UK households, based on surveyed time-use data. Also in [18], the authors investigate the pattern of electricity use in domestic dwelling in relation to the activities of the occupants. Moreover, in order to validate the model, electricity demand was recorded over the period of a year for 22 dwellings in the East Midlands in the 
United Kingdom. Widen et al. [19] present a model to compute daily electricity and hot-water demand profiles from time-use data, using simple conversion schemes, mean appliance and water-tap data and general daylight availability distributions. The model outputs, when applied to a large data set of time use in Sweden, also show correspondence to aggregate profiles for both household electricity and hot water collected by recent Swedish metering campaigns. Another interesting research [20] analyzed a dataset of hourly electricity consumption for 3989 customers measured in the course of the whole year of 2008. Through self-organizing maps and clustering techniques a typical load curves according to building use and external climatic conditions was accordingly developed.

Some interesting examples of hourly electricity use profiles developed according to the analysis of statistical data can be found in the following studies. The Canadian Hybrid Residential End-use Energy and Emission Model (CHREM) [21] was developed taking into account 17,000 detailed house records that include several types of information collected during a nine year audit and in relation to the national census. The data were then analyzed by calibrated neural network in order to estimate the annual electricity consumption and to elaborate it in hourly profiles. Another example concerns Hong Kong, where an electricity use model [22] was developed starting from a two year survey of 1516 domestic household with average monthly electricity consumption of $100 \mathrm{~kW} \mathrm{~h}$ or above, sorted by housing type, according to information directly provided by the end users. Last, the methodology followed in developing a UK non-domestic stock database [23] can also be mentioned. It considers 3350 buildings sorted per function, and combines measured records of the building fuel consumption, users' interviews and room by room inspections in developing the model.

\section{Available References in the Italian Context}

As already mentioned above, the aim of this study was to elaborate standard hourly profiles for different building functions specifically referred to the Italian context. Since the electricity use is strongly influenced by a lot of parameters that are characteristic for local conditions, such as the installed technologies, the economic conditions, the climate and the population habits (especially considering residential uses), the available data sources specifically determined for Italy were analyzed.

The data reported by Terna S.p.A. [24] and by the National Statistical Institute [25], collecting the yearly electricity consumption information for the Italian context [4], can be listed under the top-down category. Except for some particular cases, in which the hourly electricity profiles are directly provided by power utilities for particular end-users, they report yearly values that are not disaggregated for specific use (i.e., lighting, appliances or cooling devices) and therefore cannot be utilized in the framework of the present work.

Approaching the load modeling and energy estimation from a bottom-up statistical analysis point of view, on the other hand, requires large amounts of measured data, because in case of a high level of accuracy, such as the one needed to develop representative load profiles, the analyzed sample should be characterized by a comparably high level of statistical significance [26].

At the European level several studies were devoted to the characterization of electricity consumption in order to overcome the difficulties related measuring real life conditions. According to the main aims of this study, the results of three well-documented and long-lasting monitoring campaigns about electricity demand and consumption were analyzed. 
The SAVE-EURECO project (end-use metering campaign in 400 households of the European Community), reported in [27], aimed at estimating consumption trends and to evaluate the potential savings achievable in the households by substituting the existing appliances with more efficient ones. The study took place in 2000 and 2001 and monitored 100 households in all the participating countries (Denmark, Greece, Italy, Portugal and France) for at least one month each.

The Energy Intelligent Europe-REsidential MOnitoring to Decrease Energy use and Carbon Emissions in Europe (EIE-REMODECE) project, reported in [28], was carried out in twelve European countries until September 2008. It contributed to the understanding of the energy consumption trends in the European households for the different types of appliances and included information about consumers' behavior and comfort levels. The project also evaluated the existing potential electricity savings that exist in the residential sector, collecting data from more than 1300 households, with about 11,500 appliances analyzed. The data collected in Italy, however, only covered 180 buildings.

The EIE EL-TERTIARY (Monitoring Electricity Consumption in the Tertiary Sector) project [29], was carried out from July 2006 to June 2008 and involved project partners from twelve countries. The study developed a methodology to collect energy consumption data and tested it on 123 tertiary buildings, providing a database with reliable electricity consumption data. These data represent only the monitored electricity loads, connected to the specific typology and function of the surveyed buildings, and therefore cannot directly be translated in average demand profiles for typical office buildings.

Technical literature can also constitute a valid source of average data. Among the available references, some important normative ones can be considered: UNI EN 15603 [30], UNI EN 15193 [31] and UNI TS 11300-1 [32].

UNI EN 15603 [30] is a European standard addressing the evaluation of the total yearly consumption for specific buildings through calculation or measurement. Concerning electrical appliances in residential and office buildings (UNI EN 15603 does not focus on artificial lighting), the standard suggests to consider the total annual electricity consumption and also provides some reference values. However, it is also explicitly stated that, since the values strongly depend on a lot of different factors, they can largely vary, with ranges that can reach $\pm 50 \%$.

The European UNI EN 15193 [31] provides detailed artificial lighting design values, but it only reports yearly electricity consumption values (hourly profile are not provided) for some commercial buildings (dwellings are not cited).

The Italian technical standard UNI TS 11300-1 [32] provides the procedure to calculate the building heating and cooling demands. However, even in case of detailed evaluation, it only reports the overall specific thermal load, which combines all the contributions to the internal gains. Unfortunately, in this way the lighting and appliances contributions cannot be easily disaggregated and accordingly converted in electricity demand values.

\section{Development of Profiles for the Italian Context}

According to the previous section, the current statistical data that can be used for the Italian context are not extensive enough to be analyzed by the means of the mentioned bottom-up techniques, while the available literature references do not aim at defining hourly profiles. For these reasons, other suitable sources were considered. 
Among these, the Swiss Technical Worksheet SIA 2024 [33] was successfully adopted in previous works of the authors (i.e., Pahud et al. in [34]). It constitutes the main Swiss official reference for building system sizing (heating, ventilation, air conditioning, lighting, etc.) and for energy-use calculations, providing the needed assumptions for different kinds of building certifications especially in the early design stages, when no other sources (i.e., direct survey) are available, and unifying the usage data adopted in applying different norms. The Technical Worksheet defines the building uses in terms of comfort requirements in the fields of thermal comfort, acoustics, lighting and air quality. It also provides occupancy and appliance use data expressed in terms of values (person per floor area, installation power, etc.) and hourly schedules that modulate the occupancy as well as the loads of the installation, which do not operate at their nominal power all the time. These hourly schedules depend on the typical daily distributions of the people presence in the zone, that take into account, among others, the typical workday and meal times, as well as on a monthly or yearly simultaneity factor, that further adjusts the nominal values by considering a typical holiday pattern. In the framework of the electrical consumption the hourly schedule and the simultaneity factor essentially adjust the theoretical total consumption of the devices to realistic conditions. While the requirement values in the worksheet report other official federal standards, the usage patterns were derived by a huge amount of surveyed data. In order to cover most of the possible building types, a total of 44 building or even zone uses are summarized (i.e., hotels, offices, open-space offices, kitchen, living rooms, etc.). Therefore, SIA 2024 [33] was assumed as reference in the first energy simulations also considering that, for the purpose of determining electricity consumption, the Swiss context taken into account by SIA 2024 [33] is not much different from the Italian one.

\subsection{Development of Case-Study Buildings}

Within the present work, three case-study buildings were developed in order to test the modeling capabilities of the building energy behavior simulation module of the platform and in order to develop utilization patterns for the residential and office uses and to analyze their impacts on the building heating and cooling demands.

Taking into account the Italian context, several building types can be identified, differing in size, number of floors and form factor $(\mathrm{S} / \mathrm{V})$. Form factor, also called surface-to-volume ratio, is the amount of surface area per unit volume of a building and defines its compactness [35]. It is well known that building form can affect solar access and wind exposure as well as the rate of heat loss or heat gain through the external envelope.

According to the authors' experience [4,36,37] and considering the final aim of the research, two case-study buildings were taken into account as representatives of the most diffuse typologies:

- a small and compact two-storey block, representing the single or double detached buildings that are peculiar of low density housing areas and are generally characterized by a $\mathrm{S} / \mathrm{V}$ between 0.5 and 1 ;

- a five-storey rectangular building, representing the line blocks of the medium-to-high density urban areas, characterized by an average $\mathrm{S} / \mathrm{V}$ of $c a$. 0.4 .

Moreover, the case-study buildings were diversified by different purpose: the first case-study building was considered only for residential purpose (one or two family house, named Building A) 
while the second one was treated both as residential (apartments, named Building B) and commercial (offices, named Building C) building, diversifying only the glazing percentage.

In fact, the residential Buildings $\mathrm{A}$ and $\mathrm{B}$ were provided with windows covering a surface equal to $1 / 8$ of the net floor area, according to the Italian conventional practice to guarantee natural ventilation and lighting, while the office Building $\mathrm{C}$ was provided with windows covering the whole main façades, except for an opaque sill of $1.10 \mathrm{~m}$.

The main characteristics of the resulting case-study buildings are summarized in Table 1.

Table 1. Main characteristics of the case-study buildings [7,8].

\begin{tabular}{ccccc}
\hline Case study buildings & $\begin{array}{c}\text { Building A: } \\
\text { Small residential—single } \\
\text { or double detached house }\end{array}$ & $\begin{array}{c}\text { Building B: } \\
\text { Residential_line } \\
\text { block building }\end{array}$ & $\begin{array}{c}\text { Building C: Commercial } \\
\text { (offices)_line block } \\
\text { building }\end{array}$ \\
\hline Characteristics & Unit & & & \\
Net floor area & $\mathrm{m}^{2}$ & 200 & 1800 & 1800 \\
Net volume & $\mathrm{m}^{3}$ & 600 & 5400 & 5400 \\
Envelope surface & $\mathrm{m}^{2}$ & 440 & 1980 & 1980 \\
Form factor (S/V) & $\mathrm{m}^{-1}$ & 0.73 & 0.37 & 45 \\
Average glazed surface & $\%$ & 10 & 18 & 0.37 \\
\hline
\end{tabular}

\subsection{Definition of Electricity Loads}

The data reported in SIA 2024 [33] were elaborated to suit the characteristics of the case-study buildings and the results were compared to the monitored data from Alari et al. [27], Grinden and Feilberg [28] and Gruber et al. [29].

Within SIA 2024 [33], the usage pattern for the electrical devices is described by the means of an average daily and hourly schedule (differentiated for working and non-working days) that should be weighted according to the simultaneity factor taking into account the presence of holidays during the reference period. Considering the fact that the holiday schedule in Italy is different from the Swiss one but the overall amount of vacation days can be comparable, in the framework of the present work the overall yearly simultaneity factor suggested by SIA 2024 [33] was adopted. The installed power density (in $\mathrm{W} / \mathrm{m}^{2}$ ) is reported in SIA 2024 [33] with a range of possible values (between a minimum and a maximum) and an average one, according to the type and efficiency of the installed appliances (Table 2). The variability range of the installed power density can also be usefully taken into account to evaluate the application of energy efficiency measures to different building typologies.

In case of artificial lighting, differently, SIA 2024 [33] provides the number of daily working hours and the installed power density (in $\mathrm{W} / \mathrm{m}^{2}$ ) needed to comply with the required illuminance level, with a maximum value representing the use of common light sources and a minimum value representing high efficiency lamps. Moreover, it is necessary to weigh the number of daily working hours with a correction factor that takes into account the contribution of daylighting. Despite the large variability of this parameter, SIA 2024 [33] suggests adopting a standard value, corresponding to typical conditions 
in common buildings, or an optimized one, suggested in case of buildings designed in order to maximize the use of natural light (Table 2).

Table 2. Assumption for the definition of the three usage scenarios reported in SIA 2024 [33].

\begin{tabular}{ccc}
\hline Scenario & Appliances & Lighting \\
\hline Minimum & Lower limit of the installed power density & High efficiency lamps and optimized daylight savings \\
Average & Average installed power density & Standard lamps and common daylight savings \\
Maximum & Upper limit of the installed power density & Standard lamps and common daylight savings \\
\hline
\end{tabular}

\subsubsection{Residential Buildings}

Residential buildings are characterized by rooms with different functions, different usage times and different appliances; in SIA 2024 [33] we can find specific data for the various dwelling zones (such as kitchen and bedroom/living room). Therefore, a typical Italian dwelling was defined in terms of average floor area and number of rooms, according to available national statistics [25]. The resulting unit has a floor area of $94.5 \mathrm{~m}^{2}$ (Figure 1), and is characterized by four main rooms (a $10 \mathrm{~m}^{2}$ kitchen, a $20 \mathrm{~m}^{2}$ living room and two $20 \mathrm{~m}^{2}$ bedrooms) and three service rooms (such as bathrooms and distribution for a total area of $24.5 \mathrm{~m}^{2}$ ).

Figure 1. Scheme of the typical Italian dwelling considered.

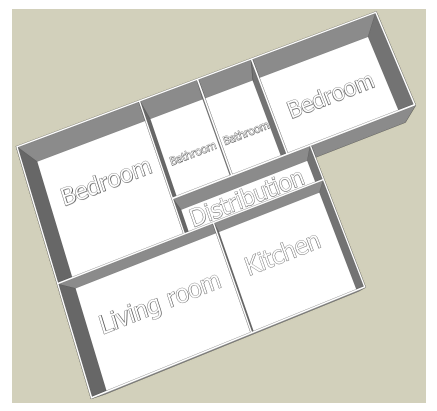

The reference hourly schedules for the whole building were then developed combining the usage patterns for the different rooms according to the specific configuration of this typical dwelling, as widely described in $[10,11]$ and are shown in Figure 2.

Figure 2. Hourly schedules for (a) appliances and (b) lighting use in residential buildings: focus on typical day.
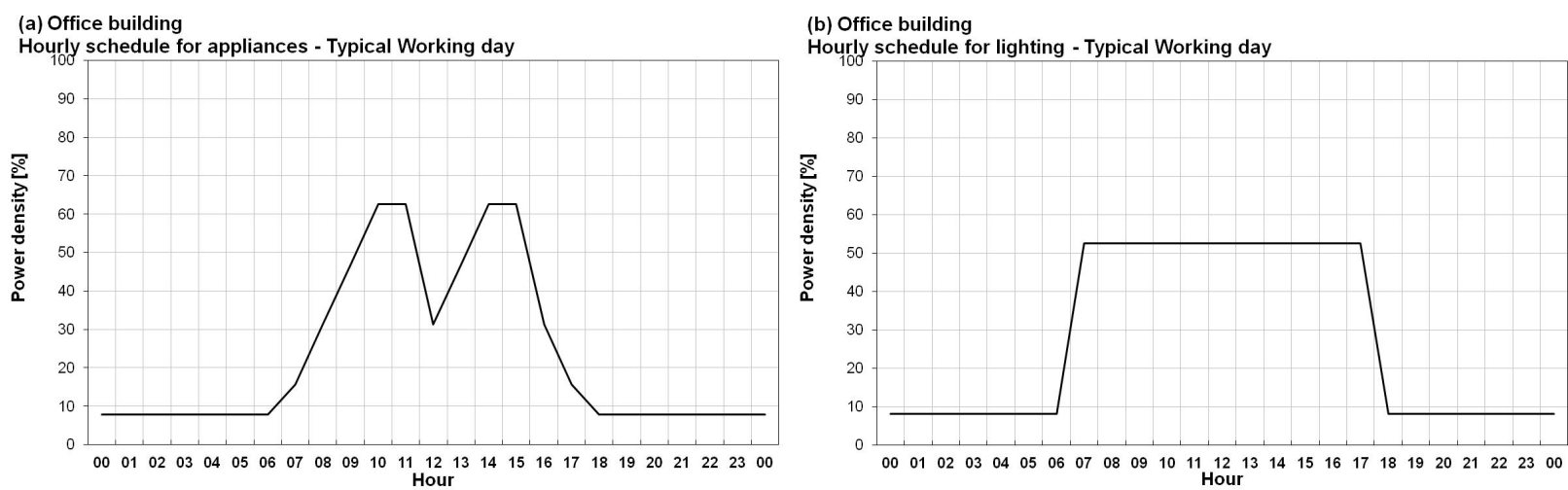
The installed power density and yearly electricity consumption for residential buildings are shown in Table 3, according to the minimum, average and maximum scenarios reported in Table 2.

Table 3. Assumption for the definition of the three usage scenarios reported in SIA 2024 [33].

\begin{tabular}{|c|c|c|c|c|}
\hline \multirow[b]{2}{*}{ Scenario } & \multicolumn{2}{|c|}{ Appliances } & \multicolumn{2}{|c|}{ Lighting } \\
\hline & $\begin{array}{l}\text { Installed power } \\
\text { density }\left(\mathbf{W} / \mathbf{m}^{2}\right)\end{array}$ & 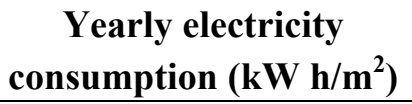 & $\begin{array}{l}\text { Installed power } \\
\text { density }\left(\mathbf{W} / \mathbf{m}^{2}\right)\end{array}$ & $\begin{array}{c}\text { Yearly electricity } \\
\text { consumption }\left(k W h / \mathbf{m}^{2}\right)\end{array}$ \\
\hline Minimum & 3.81 & 9.74 & 6.95 & 18.10 \\
\hline Average & 5.50 & 14.53 & 10.20 & 37.73 \\
\hline Maximum & 7.20 & 19.31 & 10.20 & 37.73 \\
\hline
\end{tabular}

Moreover, comparing the maximum and minimum values in Table 3, it can be noted that the yearly electricity consumption can be decreased by almost one half through the installation of more efficient devices.

\subsubsection{Office Buildings}

The approach followed to define the electricity profiles in office buildings is very similar to the one adopted for residential buildings, but in this case the floor area was simply divided in two parts: $60 \%$ of single offices (i.e., offices with maximum six occupants, as described in SIA 2024 [33]) and $40 \%$ of service and distribution areas, according to what is stated in UNI TS 11300-1 [32].

Therefore, the electricity loads for the appliances was adopted only in the office part, following the related hourly schedule and simultaneity factor. The lighting loads were adopted in the whole building during the occupied hours, while when the building is not occupied, a $20 \%$ rate of the lighting system is considered active only in the service/distribution part, for safety and security purposes. The hourly electricity loads due to appliances and lighting are widely described in [10,11] and a typical working day is shown in Figure 3.

Figure 3. Hourly schedules for (a) appliances and (b) lighting use in office buildings: focus on typical working day.
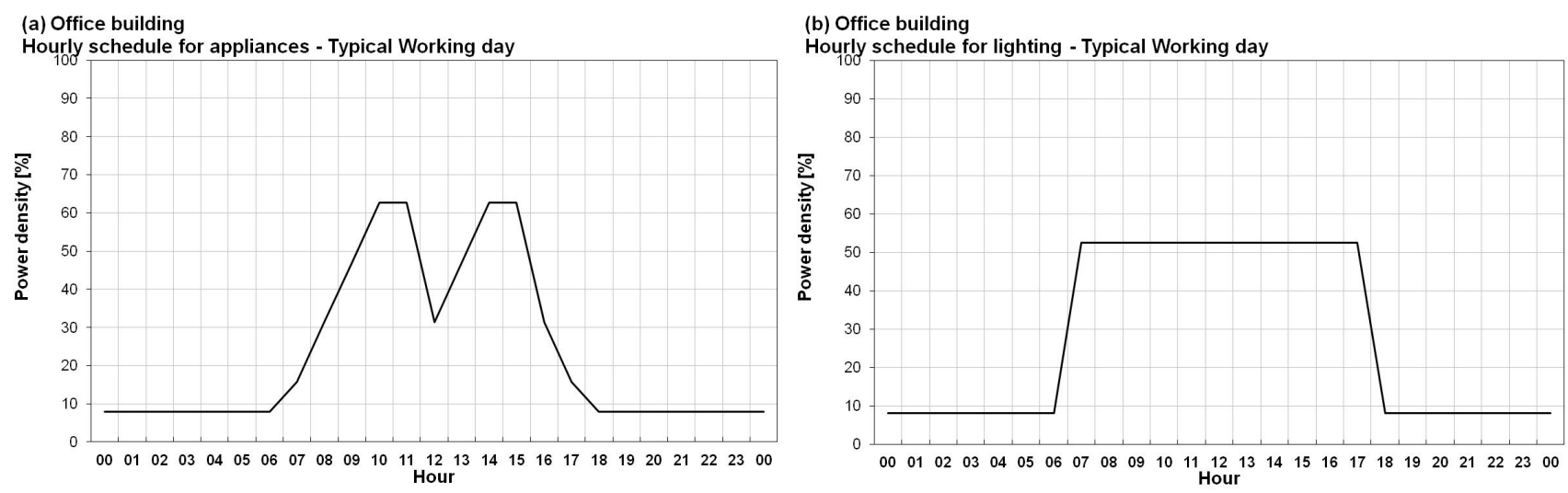

The installed power density and yearly electricity consumption for office buildings are shown in Table 4, according to the minimum, average and maximum scenarios reported in Table 2. 
Table 4. Installed power density and yearly electricity consumption for appliances and lighting in office buildings [10,11].

\begin{tabular}{cccccc}
\hline \multirow{2}{*}{ Scenario } & \multicolumn{2}{c}{ Appliances } & & \multicolumn{2}{c}{ Lighting } \\
\cline { 2 - 3 } \cline { 5 - 6 } & $\begin{array}{c}\text { Installed power } \\
\text { density }\left(\mathbf{W} / \mathbf{m}^{\mathbf{2}}\right)\end{array}$ & $\begin{array}{c}\text { Yearly electricity } \\
\text { consumption }\left(\mathbf{k W ~ h} / \mathbf{m}^{\mathbf{2}}\right)\end{array}$ & & $\begin{array}{c}\text { Installed power } \\
\text { density }\left(\mathbf{W} / \mathbf{m}^{\mathbf{2}}\right)\end{array}$ & $\begin{array}{c}\text { Yearly electricity } \\
\text { consumption }\left(\mathbf{k W} \mathbf{~ h} / \mathbf{m}^{\mathbf{2}}\right)\end{array}$ \\
\hline Minimum & 1.80 & 3.04 & 11.60 & 12.19 \\
Average & 4.20 & 7.10 & & 15.90 & 31.50 \\
Maximum & 9.00 & 15.21 & 15.90 & 31.50 \\
\hline
\end{tabular}

Once again, the installed power density values exceed the maximum hourly electricity use in Figure 3 , because they are not yet weighted by the average yearly simultaneity factor and hourly schedule.

Furthermore, the comparison of the maximum and minimum values in Table 4 show that the yearly electricity consumption can be reduced by a factor three by installing more efficient devices.

\subsubsection{Validation of the Defined Electricity Loads}

One of the aims of the work was to test the reliability of the electricity loads described in Section 3.2 in relation to the Italian conditions. To that end, the surveys and statistic reports mentioned in Section 2 were taken into account as term of comparison. Since these data and the ones included in UNI EN 15603 [31] and UNI EN 15193 [31] are reported on a yearly basis, the comparison was focused on the yearly values derived from the adopted hourly profiles. The yearly consumption values elaborated for the typical Italian dwelling described in Section 3.1 were compared with the data from buildings for three or four occupants, which are consistent with the dwelling's dimension, as reported in Alari et al. [27] and Grinden and Feilberg [28].

Figure 4 shows the comparison, sorted by number of occupants and by presence of electrical devices (minimum, average and maximum). It can be seen that most of the surveyed building typologies (except for three occupants homes with the highest number of installed appliances) are characterized by an electricity demand that remains between the minimum and the average values derived for the typical dwelling following the indications reported in (SIA 2024 [33]).

According to these results, the average profile of Table 3 was adopted for Building $\mathrm{B}$, that is occupied by apartments, usually characterized by smaller floor areas, while the minimum profile of Table 3 was adopted for Building A, which may represent larger detached or semi-detached houses. Residential buildings seem also to be characterized by a similar amount of electrical appliances regardless of the number of occupants or of the floor area (e.g., only one washing machine, dishwasher, etc.); in fact, larger dwellings always present a lower installed power per square meter. This assumption was also confirmed by a further comparison with the results of the long term consumption metering campaign of a detached $200 \mathrm{~m}^{2}$ house carried out during the REMODECE campaign [28] and in the framework of a Ph.D. thesis [38]; in fact electricity demand in this building resulted particularly close to the minimum scenario value.

Similarly, for the offices the electricity loads of Table 4 were compared to the data collected in Gruber et al. [29]. The EIE EL-TERTIARY project, reported in [29], developed and tested a methodology for collecting energy consumption data in tertiary buildings and provided a database with reliable data on electricity consumption [11]. 
Figure 4. Comparison between the yearly electricity demands for residential buildings elaborated on the basis of SIA 2024 [33] and the monitoring data extracted from Alari et al. [27] and Grinden and Feilberg [28], in MW h.

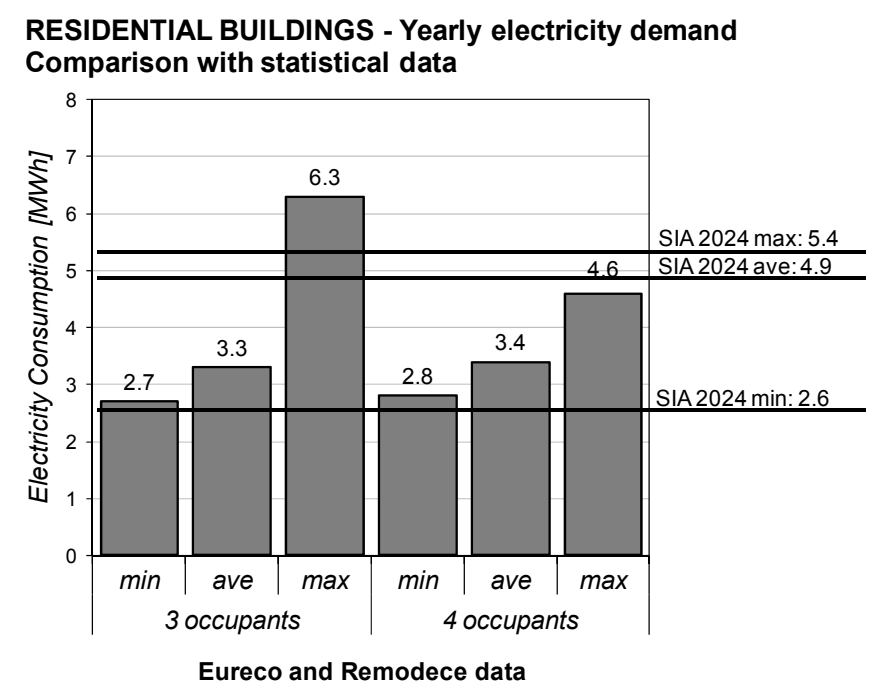

Since the number of office buildings monitored in Italy is quite small, however, the average yearly electricity consumption of all the offices monitored within the research project (i.e., 51 buildings in 12 European countries) was adopted as term of comparison (Figure 5). These data are very close to the maximum scenario defined in Table 4, therefore this profile was adopted for Building C.

Figure 5. Comparison between the yearly electricity demands for office buildings elaborated on the basis of SIA 2024 [33] and the statistical data from Gruber et al. [29], in $\mathrm{kW} \mathrm{h} / \mathrm{m}^{2}$.

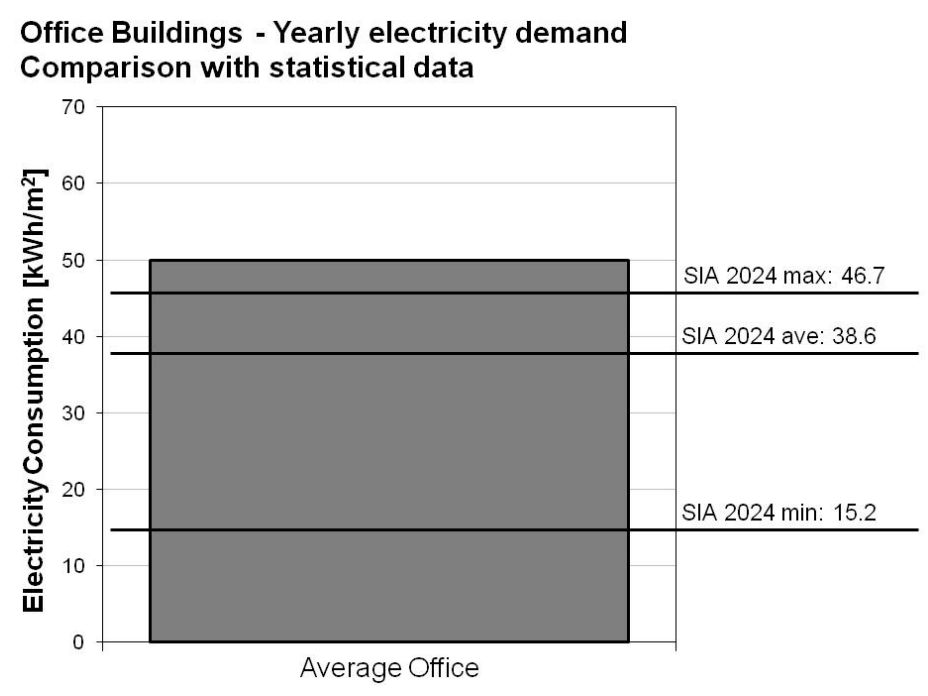

Concerning the electricity consumption for appliances, the obtained results are also compliant with the yearly values reported in UNI EN 15603 [31] for residential and office buildings. Similarly, when considering the electricity demand for lighting, the standard values shown in UNI EN 15193 [30] are comparable to those derived in the present work both in terms of installed power density $\left(\mathrm{W} / \mathrm{m}^{2}\right)$ and in terms of yearly electricity consumption $\left(\mathrm{kW} \mathrm{h} / \mathrm{m}^{2}\right)$. 
The installed power per square meter and the yearly electricity consumption for the three case-study buildings are definitively summarized in Table 5. The values result from the previously mentioned assumptions: the considered usage scenarios (Table 2), the reference dwelling and office buildings with their specific schedules and the comparison with the metered data as shown in Figures 4 and 5.

Table 5. Resulting installed power density and yearly electricity consumption for appliances and lighting in the case-study buildings [10,11].

\begin{tabular}{|c|c|c|c|c|}
\hline \multirow[b]{2}{*}{$\begin{array}{c}\text { Case-study } \\
\text { buildings }\end{array}$} & \multicolumn{2}{|c|}{ Appliances } & \multicolumn{2}{|c|}{ Lighting } \\
\hline & $\begin{array}{l}\text { Installed power } \\
\text { density }\left(W / \mathbf{m}^{2}\right)\end{array}$ & 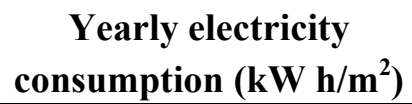 & $\begin{array}{r}\text { Installed power } \\
\text { density }\left(W / \mathbf{m}^{2}\right)\end{array}$ & 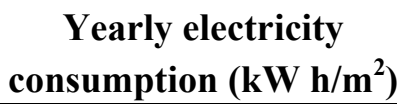 \\
\hline A & 3.81 & 9.74 & 6.95 & 18.10 \\
\hline B & 5.50 & 14.53 & 10.20 & 37.73 \\
\hline $\mathrm{C}$ & 9.00 & 15.21 & 15.90 & 31.50 \\
\hline
\end{tabular}

\subsection{Related Internal Gains}

As previously mentioned, the electricity demand profiles are very important in the framework of energy planning at the building and district scales, not only because of the electricity consumption, generation and management, but also because of their thermal effects. The internal gains due to lighting, appliances and occupancy are therefore here evaluated as results of dynamic simulations performed for the three case-study buildings by the means of the software TRNSYS 16 [39]. In the following tables (Tables 6 and 7) the main adopted simulation settings are explained.

Table 6. TRNSYS simulations settings. ACH: the air changes per hour.

\begin{tabular}{|c|c|c|c|c|}
\hline \multicolumn{2}{|c|}{ Simulations settings/Case-study buildings } & Building A & Building B & Building $\mathrm{C}$ \\
\hline \multicolumn{2}{|c|}{ Infiltration $\left(\mathrm{ACH}\right.$ in $\left.\mathrm{h}^{-1}\right)$} & 0.200 & 0.200 & 0.200 \\
\hline \multicolumn{2}{|c|}{ Natural ventilation ${ }^{\mathrm{a}}\left(\mathrm{ACH}\right.$ in $\left.\mathrm{h}^{-1}\right)$} & 0.562 & 0.562 & $1.690^{\mathrm{b}}$ \\
\hline \multirow{3}{*}{ Heating period } & Milan (MI) & $15 / 10-15 / 04$ & $15 / 10-15 / 04$ & $15 / 10-15 / 04$ \\
\hline & Rome (RM) & $1 / 11-15 / 04$ & $1 / 11-15 / 04$ & $1 / 11-15 / 04$ \\
\hline & Palermo (PA) & $1 / 12-31 / 03$ & $1 / 12-31 / 03$ & $1 / 12-31 / 03$ \\
\hline \multirow{3}{*}{ Cooling period } & Milan (MI) & $16 / 04-14 / 10$ & $16 / 04-14 / 10$ & $16 / 04-14 / 10$ \\
\hline & Rome (RM) & $16 / 04-31 / 10$ & $16 / 04-31 / 10$ & $16 / 04-31 / 10$ \\
\hline & Palermo (PA) & $1 / 04-30 / 11$ & $1 / 04-30 / 11$ & $1 / 04-30 / 11$ \\
\hline
\end{tabular}

a: For the residential buildings, a constant value of natural ventilation was adopted, regardless of the occupancy schedule, as in this kind of buildings is very difficult to find a match between use and natural ventilation. Differently, for the office building the ventilation rate was modulated on the basis of the occupancy profile, in order to get a reliable evaluation of internal loads. In office buildings, the maximum number of air changes considered is equal to $1.89 \mathrm{ACH}$, divided in $0.2 \mathrm{ACH}$ due to infiltration and $1.69 \mathrm{ACH}$ due to natural ventilation $(0.64 \mathrm{ACH}$ to regulate the air contamination from building features and $1.05 \mathrm{ACH}$ to regulate the $\mathrm{CO}_{2}$ level due to people presence). The maximum value of $1.68 \mathrm{ACH}$ of natural ventilation (in case of full occupancy) is modulated during the day on the basis of office occupancy schedule; b: the maximum value, in case of full occupancy. 
Table 7. Percentage of heat emission features for lighting, equipments, and occupants.

\begin{tabular}{cccc}
\hline $\begin{array}{c}\text { Percentage of heat emission features for lighting, } \\
\text { equipments, and occupants }\end{array}$ & Lighting & Appliances & Occupants \\
\hline Convective fraction & 40 & 80 & 67 \\
Radiant fraction & 60 & 20 & 33 \\
\hline
\end{tabular}

Since the references $[10,11]$ focused on the Italian context, the three case-study buildings were simulated in three locations that can represent the wide variety of the Italian climatic conditions: Milan (MI), which has a continental climate characterized by cold winter and warm summer, Rome (RM), which has a Mediterranean climate characterized by mild winter and warm summer with higher incidence of solar radiation, and Palermo (PA), which has a Mediterranean climate characterized by even milder winter and warmer summer due to the higher air temperature.

Moreover, regardless of climate and location, the case-study buildings were modeled with envelopes that are typical of the Italian construction common practice in relatively recent times, with opaque structures with an average $U$-value of $0.39 \mathrm{~W} /\left(\mathrm{m}^{2} \mathrm{~K}\right)$ and double glazing with a $U$-value of $2.35 \mathrm{~W} /\left(\mathrm{m}^{2} \mathrm{~K}\right)$ and a solar energy transmittance of glass ( $g$-value) of 0.57 .

Concerning occupancy, in SIA 2024 [33], it is described according to an average daily and hourly schedule (differentiated for working and non-working days) that should be weighed according to the same simultaneity factor used for the appliances. Hourly occupancy schedule during the typical week (with yearly average simultaneity factor) for residential and office buildings are widely described in $[7,8]$.

The specific hourly occupancy schedule for a typical day of a residential building and for a typical working day of an office building are described in Figure 6, respectively.

Figure 6. Specific hourly occupancy schedules for (a) residential building and (b) office building. Minimum, average and maximum scenarios.


This hourly profile modules the presence of the people, that is represented both by a floor area per occupant (in $\mathrm{m}^{2}$ /person) and by the related sensible heat flow density (in $\mathrm{W} / \mathrm{m}^{2}$ ), that are specified by a range of possible values (between a minimum and a maximum) and by an average one. The thermal load values due to the presence of people for the three case-study buildings are reported in Table 8 according to the already assigned scenarios. 
Table 8. Heat gains due to the presence of people for the case-study buildings (yearly productions evaluated by TRNSYS 16) [7,8].

\begin{tabular}{cccc}
\hline Heat gains/Case-study buildings & A & B & C \\
\hline Specific load $\left(\mathrm{W} / \mathrm{m}^{2}\right)$ & 1.85 & 2.43 & 3.90 \\
Yearly production $\left(\mathrm{kW} \mathrm{h} / \mathrm{m}^{2}\right)$ & 5.25 & 7.32 & 4.80 \\
\hline
\end{tabular}

In the simulations, the air changes per hour were derived from EN ISO 15251 [40], according to the occupancy schedules provided by SIA 2024 [33].

The contribution of the internal gains to the resulting buildings' heating and cooling demands are analyzed in detail in the previous works by the authors $[10,11]$. This contribution varies in accordance with the overall yearly internal heat production, with Building A as the less affected by the gains and Building $\mathrm{B}$ as the most affected one, and can constitute a significant portion of the overall climatization demand (between $10 \%$ and $60 \%$ for heating and between $50 \%$ and $80 \%$ for cooling).

\subsection{Comparison to the Internal Gains Calculated as Proposed by UNI TS 11300-1 [32]}

As mentioned in Section 2, UNI TS 11300-1 [32] is the current Italian technical standard about the procedure and data required to calculate the building heating and cooling demand. It allows both a "design or standard evaluation", which is based on an average hourly value per unit area according to the building use, and a "detailed analysis evaluation", that suggests reference hourly profiles for the residential and office uses, dividing the floor area in a main and a service part. As explained above, UNI TS 11300-1 [32] suggests the calculation of the overall internal gains due to the combination of artificial lighting, appliances and occupancy.

Figure 7 shows the comparison between the yearly internal gains obtained as results of the TRNSYS simulations for Buildings $\mathrm{A}$ and $\mathrm{B}$ and those derived as elaborations following UNI TS 11300-1 [32] for both the "design or standard evaluation" and the "detailed analysis evaluation". Both the values derived from the Italian standard, but in particular the one referred to "detailed analysis evaluations", are comprised between the reference scenarios for the residential buildings.

Figure 7. Comparison of the yearly internal heat production for Buildings $A$ and $B$

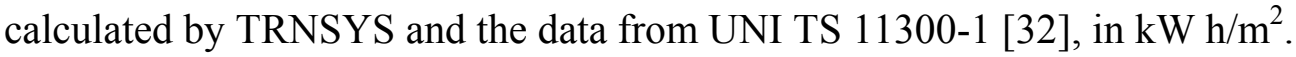

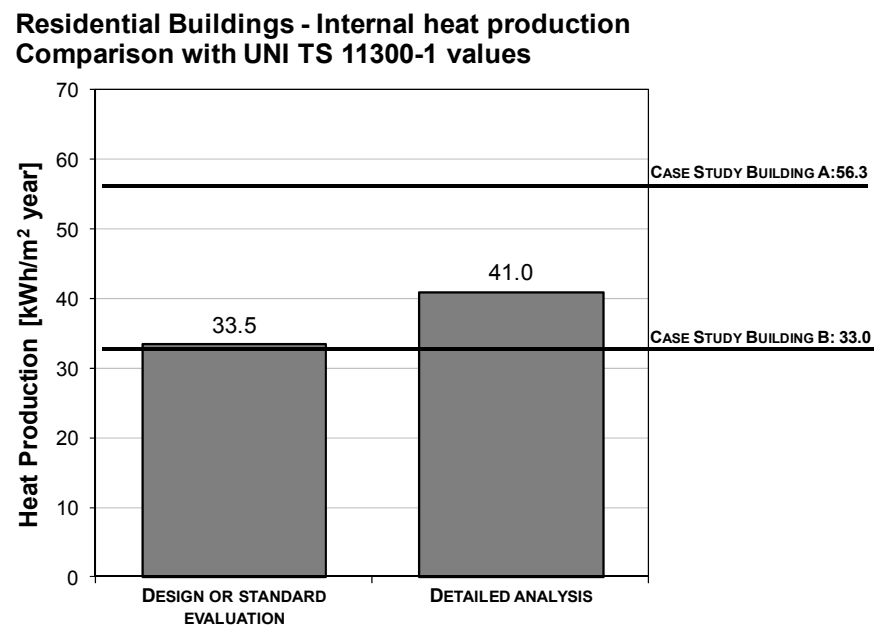

UNI TS 11300-1 values 
The same procedure was followed for Building C, as shown in Figure 8. The "design or standard evaluation" and in particular the "detailed analysis evaluation" determine results that are quite similar to the reference scenario for the office building.

Figure 8. Comparison of the yearly internal heat production for Building $\mathrm{C}$ calculated by TRNSYS and the chosen scenario and the data from UNI TS 11300-1 [32], in $\mathrm{kW} \mathrm{h} / \mathrm{m}^{2}$.



\section{Conclusions and Future Developments}

As already mentioned, the definition of reliable electricity profiles in buildings is a very complex matter, due to the fact that they are largely variable and depend on many different factors. Nevertheless, some basic considerations can be argued. In the case of residential buildings it is very hard to define reference values in terms of electricity consumption per floor area, because they actually depend on buildings characteristics, number of occupants, availability and characteristics of appliances, which are difficult to estimate and are not directly proportional to the dwelling size. In commercial buildings, the analysis is even more difficult, due to the amount of possible building typologies and to the disparately different practices in electrical appliances use.

Despite all these considerations and the previously described assumptions and limitations, the values reported in Table 5 could be taken into account for dynamic energy simulations of residential and office buildings and, as benchmark, in energy efficiency measures evaluations.

The approach adopted by SIA 2024 [33], which combines elaboration from official standards with the results of extensive national surveys, has proven to be effective in providing reference profiles, at least in contexts characterized by a built environment and behaviors that do not significantly differ from the Swiss ones. The comparison of electricity demand values resulting from this work with the monitored data reported by Alari et al. [27], Grinden and Feilberg [28] and Gruber et al. [29] confirms the reliability of the data of SIA 2024 [33] also in the Italian context, at least at the yearly level. The same can be stated in relation to the heat gains, which were compared to the results of the procedure described in UNI TS 11300-1 [32]. 
The authors hope that the present paper can be of support in some key building related issues in the framework of energy simulations, such as the definition of electricity and occupancy profiles in buildings and the analyses of the related effects on comfort in terms of heating and cooling loads.

However, as described in Section 2, it would be necessary to collect extensive amounts of data from real case-studies if the purpose is to develop reliable, more refined and locally dependent hourly profiles that are able to give high resolution information or forecasting information for supporting electricity supply tools or demand-supply tools.

According to Swan and Ugursal [20], these can be gathered through the vast quantity of customer energy billing information stored at the energy suppliers. In some particular cases [41], power utilities may provide electricity data. This is the case, for example, of the city of Parma, a community of 180,000 inhabitants located in the North of Italy, taken into account as case study in $[42,43]$.

Moreover the diffusion of more effective technologies such as the smart metering instruments and tools will increase the amount of available data [4] and facilitate their analysis in order to characterize specific electricity consumptions and internal heat load profiles related to the buildings functions.

Measured energy performance data are indeed essential to improve building efficiency and, as shown in Granderson et al. [44], the value of permanent monitoring and energy information feedback and the consequent active role of users are very relevant to reach this goal.

This opportunity can be also supported by the recent European Directive on energy efficiency [45], stating that individual and accurate information about the real time energy consumption shall be provided to final customers.

\section{Acknowledgments}

The authors thank Ilaria Bertini and other colleagues of her working group of the Italian Agency for New Technologies, Energy and Sustainable Economic Development (ENEA). Among them, a particular thought goes to Francesco Ceravolo. Finally a special thanks also to Andrea Roscetti, for the stimulating data and information.

\section{Conflicts of Interest}

The authors declare no conflict of interest.

\section{References}

1. European Institute for Energy Research (EIFER). Available online: http://www.eifer.unikarlsruhe.de/ (accessed on 22 March 2013).

2. EIFER 2.0. Available online: http://www.eifer.uni-karlsruhe.de/IMG/pdf/120417_eifer_ broschuere_ansicht_web.pdf (accessed on 22 March 2013).

3. European Commission. Directive 2010/31/EU of the European Parliament and of the Council of 19 May 2010 on the energy performance of buildings (recast). Off. J. Eur. Union 2010, L153, $13-35$.

4. Caputo, P.; Costa, G.; Ferrari, S. A supporting method for defining energy strategies in the building sector at urban scale. Energy Policy 2013, 55, 261-270. 
5. Energy Roadmap 2050; European Commission: Brussels, Belgium, 2011.

6. Cruz-Peragon, F.; Palomar, J.M.; Casanova, P.J.; Dorado, M.P.; Manzano-Agugliaro, F. Characterization of solar flat plate collectors. Renew. Sustain. Energy Rev. 2012, 16, 1709-1720.

7. Manzano-Agugliaro, F.; Alcayde, A.; Montoya, F.G.; Zapata-Sierra, A.; Gil, C. Scientific production of renewable energies worldwide: An overview. Renew. Sustain. Energy Rev. 2013, 18, 134-143.

8. Baños, R.; Manzano-Agugliaro, F.; Montoya, F.G.; Gil, C.; Alcayde, A.; Gómez, J. Optimization methods applied to renewable and sustainable energy: A review. Renew. Sustain. Energy Rev. 2011, 15, 1753-1766.

9. Bahaj, A.S.; Myers, L.; James, P.A.B. Urban energy generation: Influence of micro-wind turbine output on electricity consumption in buildings. Energy Build. 2007, 39, 154-165.

10. Caputo, P.; Costa, G.; Pistocchini, L.; Roscetti, A.; Zanotto, V. Strumenti e Tecnologie per L'efficienza Energetica nel Settore dei Servizi, Comportamento della Piattaforma in Relazione al Corretto Abbinamento tra Curve di Domanda e Sistemi di Generazione e Controllo (in Italian); Final Report to Agenzia Nazionale per le Nuove Tecnologie, 1'Energia e lo Sviluppo Economico Sostenibile: Rome, Italy, 2011.

11. Caputo, P.; Costa, G.; Roscetti, A.; Zanotto, V. Electric Loads in Residential and Office Buildings in Italy. In Proceedings of the 2nd International Congress MACDES, La Habana, Cuba, 6-9 December 2011.

12. ENEA. Download Page for ODESSE. Available online: http://www.enea.it/it/Ricerca_sviluppo/ ricerca-di-sistema-elettrico/Risparmio-energia-elettrica/tecnologie-per-lefficienza-energetica-neiservizi/odesse-1/download-del-software-odesse (accessed on 22 March 2013).

13. Sánchez, P.; Montoya, F.G.; Manzano-Agugliaro, F.; Gil, C. Genetic algorithm for S-transform optimisation in the analysis and classification of electrical signal perturbations. Expert Syst. Appl. 2013, 40, 6766-6777.

14. Swan, L.G.; Ugursal, V.I. Modeling of end-use energy consumption in the residential sector: A review of modelling techniques. Renew. Sustain. Energy Rev. 2009, 13, 1819-1835.

15. Manfren, M.; Caputo, P.; Costa, G. Paradigm shift in urban energy system through distributed generation: methods and models. Appl. Energy 2011, 88, 1032-1048.

16. Chioua, Y.-S.; Carleyc, K.M.; Davidsond, C.I.; Johnsone, M.P. A high spatial resolution residential energy model based on American Time Use Survey data and the bootstrap sampling method. Energy Build. 2011, 43, 3528-3538.

17. Richardson, I.; Thomson, M.; Infield, D. A high-resolution domestic building occupancy model for energy demand simulations. Energy Build. 2008, 40, 1560-1566.

18. Richardson, I.; Thomson, M.; Infield, D.; Clifford, C. Domestic electricity use: A high-resolution energy demand model. Energy Build. 2010, 42, 1878-1887.

19. Widen, J.; Lundh, M.; Vassileva, I.; Dahlquist, E.; Ellegard, K.; Wackelgard, E. Constructing load profiles for household electricity and hot water from time-use data-Modelling approach and validation. Energy Build. 2009, 41, 753-768.

20. Räsänen, T.; Voukantsis, D.; Niska, H.; Karatzas, K.; Kolehmainen, M. Data-based method for creating electricity load profiles using large amount of customer-specific hourly measured electricity use data. Appl. Energy 2010, 87, 3538-3545. 
21. Swan, L.; Ugursal, V.I.; Beausoleil-Morrison, I. Implementation of a Canadian Residential Energy End-Use Model for Assessing New Technology Impact. In Proceedings of the 11th International Building Performance Simulation Association (IBPSA) Conference, Glasgow, Scotland, UK, 27-30 July 2009; pp. 1429-1436.

22. Tso, G.K.F.; Yau, K.K.W. A study of domestic energy usage patterns in Hong Kong. Energy 2003, 28, 1671-1682.

23. Mortimer, N.D.; Ashley, A.; Elsayed, M.; Kelly, M.D.; Rix, J.H.R. Developing a database of energy use in the UK non-domestic building stock. Energy Policy 1999, 27, 451-468.

24. Terna S.p.A. Available online: http://www.terna.it (accessed on 22 March 2013).

25. Italian National Institute of Statistics (ISTAT). Available online: http://www.istat.it (accessed on 22 March 2013).

26. Pedersen, L. Load Modelling of Buildings in Mixed Energy Distribution Systems. Ph.D. Thesis, Norwegian University of Science and Technology, Trondheim, Norway, 2007.

27. Alari, P.; Fraternali, D.; Pagliano, L.; Pindar, A. The Eureco Project. Measurements and Analysis of Energy Consumption and Power Load Profiles of Refrigeration, Space Conditioning, Heating Ancillary Equipment and Other Appliances in 410 Households. In Proceedings of the UNESCO International School of Science for Peace, Como, Italy, 5-8 July 2000; pp. 343-347.

28. Grinden, B.; Feilberg, N. Analysis of Monitoring Campaign in Europe; Residential Monitoring to Decrease Energy Use and Carbon Emissions in Europe: Coimbra, Portugal, 2008.

29. EL-TERTIARY. Monitoring Electricity Consumption in the Tertiary Sector. Available online: http://www.eu.fhg.de/el-tertiary/ (accessed on 22 March 2013).

30. Energy Performance of Buildings-Energy Requirements for Lighting; European Committee for Standardization: Brussels, Belgium, 2008.

31. Energy Performance of Buildings-Overall Energy Use and Definition of Energy Ratings; European Committee for Standardization: Brussels, Belgium, 2008.

32. UNI TS 11300-1. Prestazioni Energetiche degli Edifici-Parte 1: Determinazione del Fabbisogno di Energia Termica Dell'edificio per la Climatizzazione Estiva ed Invernale (in Italian); Ente Nazionale Italiano di Unificazione: Milano, Italy, 2008.

33. SIA Merkblatt 2024. Standard-Nutzungsbedingungen für die Energie- und Gebäudetechnik (in German); Swiss Society of Engineers and Architects: Zürich, Switzerland, 2006.

34. Pahud, D.; Belliardi, M.; Caputo, P. Geocooling potential of borehole heat exchangers' systems applied to low energy office buildings. Renew. Energy 2012, 45, 197-204.

35. Energy and Resources Institute; Institut Catalá d'Energia; Asia Urbs Programme. Sustainable Building-Design Manual: Sustainable Building Design Practices; TERI Press: New Delhi, India, 2004.

36. Costa, G. Caratterizzazione Tecnologico-Prestazionale del Patrimonio Edilizio per la Valutazione Dell'efficacia di Strategie Energetiche (in Italian). Ph.D. Thesis, Politecnico di Milano, Milano, Italy, 2012.

37. Caputo, P.; Costa, G.; Ferrari, S. A Methodology for Assessing Energy Performance of a Large Scale Building Stock. In Proceedings of the 2nd International Congress MACDES, La Habana, Cuba, 6-9 December 2011. 
38. Zangheri, P. Extension of Passivhaus Concept to Warm Climates and Development of Optimisation Procedures for Low Energy Buildings Using Various Comfort Models. Ph.D. Thesis, Politecnico di Milano, Milano, Italy, 2009.

39. TRNSYS 16-A Transient System Simulation Program - User Manual; The Solar Energy Laboratory, University of Wisconsin: Madison, WI, USA, 2007; Volume 8.

40. Indoor Environmental Input Parameters for Design and Assessment of Energy Performance of Buildings Addressing Indoor Air Quality, Thermal Environment, Lighting and Acoustics; European Committee for Standardization: Brussels, Belgium, 2006.

41. Iren Emilia. Available online: http://www.irenemilia.it (accessed on 22 March 2013).

42. Manfren, M. Sistemi ad Alta Efficienza per la Generazione Distribuita a Scala Urbana (in Italian). Ph.D. Thesis, Politecnico di Milano, Milano, Italy, 2009.

43. Caputo, P.; Angelotti, A.; Costa, G. Energy Transition in Parma City. In Proceedings of the Future for Sustainable Built Environments with High Performance Energy Systems Congress, Munich, Germany, 19-21 October 2010; pp.150-157.

44. Granderson, J.; Piette, M.A.; Ghatikar, G. Building energy information systems: user case studies. Energy Effic. 2011, 4, 17-30.

45. European Commission. Directive 2012/27/EU of the European Parliament and of the Council of 25 October 2012 on energy efficiency, amending Directives 2009/125/EC and 2010/30/EU and repealing Directives 2004/8/EC and 2006/32/EC. Off. J. Eur. Union 2012, L315, 1-56.

(C) 2013 by the authors; licensee MDPI, Basel, Switzerland. This article is an open access article distributed under the terms and conditions of the Creative Commons Attribution license (http://creativecommons.org/licenses/by/3.0/). 